\title{
Conceptos no humanos: las significaciones del Ser en alteridad Jesús Emmanuel Ferreira González
}

\author{
José Alfonso Villa Sánchez
}

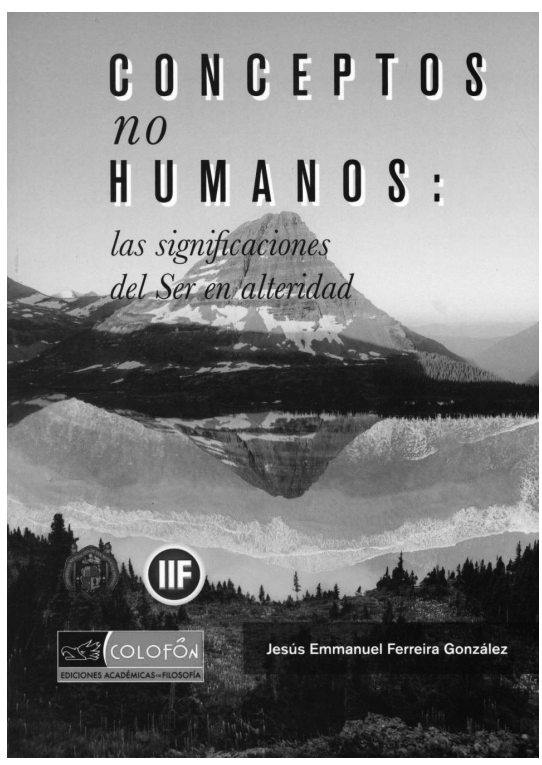

Jesús Emmanuel Ferreira González, Conceptos no humanos: las significaciones del Ser en alteridad. Ciudad de México: Colofón, 2017.
La filosofía del siglo xx fue haciéndose sobre varios derroteros que tienen de fondo la motivación común por la necesidad de remontar el ámbito de la representación. Lo anterior, en un abanico que va desde la esfera epistemológica y científica hasta la política, pasando por la esencia del arte y la de la propia técnica, comprendida por Heidegger, no como mero instrumento, sino como un ámbito en el que el sentido del ser del ente se ofrece de suyo de una manera precisa. Además de Heidegger -también como depositario de la herencia venida de Kierkegaard y Nietzsche-, deben inscribirse en esa lista de filósofos anti representacionistas a Maurice Merleau-Ponty y Emmanuel Lévinas. El estudio de 
Emmanuel Ferreira se inscribe, ya hacia el final de la segunda década del siglo XXI, en esta estela: mediando entre ambos herederos de Husserl -y del propio Heidegger-, Ferreira tiene la audaz pretensión de ser más radical que ellos, al romper desde el interior la filosofía moderna que identifica ser y pensamiento, concediéndole la iniciativa siempre a la realidad, al ser, y no a la razón. Entonces, remontar la filosofía de la representación significa también horadar la identidad que nivela el ser y el pensar.

La investigación tiene claro el objetivo de remontar el ámbito de la representación, tal como se fue consagrando en la historia intelectual de Europa en la época moderna:

Lo que aquí se presenta es una crítica al pensamiento conceptual de la representación, abstracción y objetividad centrado en la conciencia subjetiva y producto de esta, característico de la filosofía occidental moderna, que trabaja con unidades de comprensión bajo la "fórmula de la identidad" que, por su modo de ser, al formalizar y constituir conceptos, pierde la esencia vital de la realidad que piensa, porque la reduce a una creación propia de la artificialidad del pensamiento, es decir, rebaja la realidad viva a "significaciones muertas", reduce la presencia del Ser a representaciones, las forma o expresiones propias del Ser a conceptos del pensamiento humano, la otredad del Ser a la mismidad del pensamiento. ${ }^{1}$

Estos renglones condensan muy bien el programa de trabajo, lo que en él se pretende someter a crítica y la propuesta que emana de ahí. El pensamiento moderno es conceptual, abstracto, objetivante; en una palabra, reductivo de la riqueza, la profundidad y la complejidad del Ser. Que el pensamiento, heredado de la época anterior, fuera reconducido por los rumbos de la objetividad y la subjetivad, trajo para el mundo grandes ventajas y desventajas frente a la época inmediatamente anterior. Pero es hora de volver la mirada 
sobre los alcances y los límites que lleva consigo entender el pensamiento de esa manera; es hora de operar sobre la categoría metafísica de la identidad entre el pensamiento y lo que es pensado una deconstrucción que libere al Ser de esa circunscripción.

¿Qué otro modo de pensar es posible, diferente a la abstracción que objetiva?, ¿¿de qué otra manera puede ejercitarse el pensamiento de modo que el Ser tenga posibilidades de ofrecerse, mucho más allá de lo que permite el binomio objetividad-subjetividad? Esto es precisamente lo que ya no está tan claro: porque acusados los conceptos abstractos de ser "significaciones muertas" se pretende una filosofía que piense con base en "significaciones vivas". Pero, ¿̇todas aquellas significaciones en realidad no tienen nada qué decir, están literalmente muertas? Una afirmación tan fuerte requiere matices en su audacia. ¿Qué tipo de pensamiento se pretende ofrecer con la expresión de "significaciones vivas"? No unas construcciones del pensamiento subjetivo, sino las mismas:
[...] formas del Ser en estado de otredad que interrumpen tanto el pensamiento -rompiendo todos los esquemas de la subjetividad-, como a la realidad del ser-del-aparecer -agrietando al fenómeno-, acaeciendo en su elemento esencial, en movimiento presencial, vivo, real, en energía fluyendo, desde su propia alteridad. ${ }^{2}$

A la fórmula de la identidad que le exige el pensamiento al Ser, a través de su objetivación, se le enfrenta la fórmula que pretende pensar el "Ser en estado de otredad", es decir, el Ser en tanto que otro, el pensamiento que lo piensa, y más que ese pensamiento. El Ser ofrece significaciones vivas, pero, ¿a quién se las ofrece? No a un hombre que es un sujeto individual y racional, pero tampoco ofrece de sí su aparecer, su presencia fenoménica. Lo que se ofrece es su riqueza, se ofrece de suyo: su realidad, su movimiento, su energía; en suma, su radical alteridad respecto del pensamiento que lo piensa. Incluso cuando lo que es tiene la fortuna de venir de expresiones vivas, conserva su

2 Ferreira, Conceptos no humanos, 22. 
alteridad radical respecto de esas expresiones, porque es más que lo que ellas expresan. Lo que es -el Ser- y el pensamiento tienen un punto de cruce por el que el pensamiento es pensamiento; pero no puede decirse lo mismo respecto de lo que es, pues la esencia del ser no es ser pensado: el ser es otro que el pensamiento -aunque tal cosa sea posible sólo en el pensamiento-. El binomio ser-pensamiento está desnivelado ontológicamente por la densidad omnicomprensiva del Ser sobre el propio pensamiento, pues es la realidad del pensamiento la que depende de la realidad de lo que es.

¿Cómo se le puede llamar a ese pensamiento que, no dependiendo de sí mismo, depende de la realidad de lo que es?

Podemos llamarle "pensamiento del Afuera” porque piensa el afuera de la conciencia; "pensamiento abierto" porque se abre a lo otro que el pensamiento; "pensamiento en otredad", porque tiene como piedra angular las formas del Ser en su condición de ser otra cosa que una significación producida por la subjetividad (dicho pensamiento se da cuenta de que, aquello que está presente ante él no tiene la formalidad que comúnmente él construye o produce); pero más puntualmente podemos llamarlo "pensamiento interrumpido", porque no es un movimiento del pensamiento, sino un momento de la realidad en el que la otredad radical irrumpe ante el pensamiento, mostrando su ser. ${ }^{3}$

Los apelativos para el pensamiento que intenta esta filosofía - "del Afuera", "abierto", "en otredad", "interrumpido"- subrayan que es el Ser quien irrumpe en el pensamiento; o, según la expresión de Zubiri, que en la intelección es lo real, por su propia iniciativa, lo que se hace presente en la inteligencia.

¿Por qué la expresión -que remite a Le Clézio- de "pensamiento interrumpido" parece ser la mejor para un pensamiento que quiere reconocer los excesos de ser negados por el pensamiento abstracto y conceptual? Porque: 
[...] el pensamiento es intervenido por las "formas del Ser en estado de otredad". Momento en el que el absoluto establece una relación, sí, pero una relación de desfase, de desajuste, de quiebre, porque no articula una correlación continua e identitaria. Relación desencajada en la que, sin embargo, el Ser le hace comprender "algo otro" al pensamiento, algo que viene desde el Ser, su elemento esencial, y se lo hace aprehender como una "escena de realidad". ${ }^{4}$

¿Se puede colegir, de la primera línea de esta afirmación, que el pensamiento tiene su propia realidad, antes de pensar lo que es? Si así fuera, el pensamiento vendría a ser un ente, tal como le sucede al ser en el pensamiento conceptual. Pero si el pensamiento no es un ente sino un acto, entonces el pensamiento es pensamiento sólo cuando está pensando el Ser. El mismo esfuerzo por liberar al ser del ente ha de llevarse a cabo para que el pensamiento se conserve en la fuerza de su actuación, lejos de su recaída en una nueva entificación. Así, el pensamiento no es un ente paralelo al Ser, interrumpido, muy a su pesar, en su propia marcha de manera ocasional.

El apoyo para internarse por el difícil terreno en el que el Ser excede siempre el pensamiento en el que se hace presente le viene a la investigación de un dominio solvente de la filosofía de Merleau-Ponty y de Lévinas:

Los dos filósofos muestran "significaciones" que no son, en su totalidad, construcciones de la subjetividad, aunque todavía conservan su fundamento o apoyo en la subjetividad, uno en el cuerpo y otro en el sentimiento ético, que es lo que vamos a cuestionar para mostrar una significación que no tiene su apoyo en la subjetividad, ni como "corporeidad", ni como "sí mismo sin identidad", sino en el movimiento del Ser. ${ }^{5}$

La tesis parallevara cabo el diálogo entre estos dos filósofos en un pensamiento radical sobre la otredad es la siguiente:

\footnotetext{
Ferreira, Conceptos no humanos, 23.

Ferreira, Conceptos no humanos, 34.
} 
[...] a pesar de las diferencias radicales entre ellos, hay una similitud en sus filosofías, en el aspecto de que ambos expresan filosofía de la no-identidad: el primero, una racionalidad de la ambigüedad (entre identidad y otredad) o filosofía en estado naciente (antes-de-la-identidad) y, en el segundo, una racionalidad de la alteridad que opera bajo la fórmula de lo sin-identidad. ${ }^{6}$

La crítica a estas dos posturas deviene en Ferreira en esa arrojada propuesta de unas significaciones no subjetivas del Ser en alteridad. 